\title{
К ВОПРОСУ О ПРОИСХОЖДЕНИИ ПРАВА И ПРАВОВОГО НИГИЛИЗМА. СОЦИАЛЬНО-ФИЛОСОФСКИЙ АНАЛИЗ
}

\section{TO THE QUESTION OF THE ORIGIN OF LAW AND LEGAL NIHILISM. SOCIAL-PHILOSOPHICAL ANALYSIS}

V. Belkin

Summary: The article deals with the issue of the birth of legal nihilism in a broad historical context of the origin of the state and law.

Keywords: legal nihilism, norm, justice, politics, legal culture, legal conscience, state, person.
Белкин Василий Владимирович

Соискатель, Пермский государственный национальный исследовательский университет consigliori2003@mail.ru

Аннотация: В статье рассматривается вопрос зарождения правового нигилизма в широком историческом контексте происхождения государства и права.

Ключевые слова: правовой нигилизм, норма, справедливость, политика, правовая культура, правосознание, государство, личность.

философии. Человек как биосоциальное существо, выделившееся из мира природы, из объективной необходимости вынужден взаимодействовать как с природой, так и другими индивидами для удовлетворения своих потребностей. Действуя из своих интересов, человек осуществляет и создает общественную связь, которая в первую очередь проявляется в процессе совместного производства средств обеспечения, как индивидуальной, так и родовой жизни.

В первобытную эпоху, субъектом, носителем родовой человеческой сущности был нераздельный коллектив род, в котором все составляющие его члены фактически составляли один организм. Индивидуальное и коллективное бытие было неразличимо, однако на определенном этапе производства возникает необходимость распределить различные производственные операции между индивидами.

Именно при переходе от неразрывного коллективного труда к частичному кооперативному труду и обмену его результатами происходит фундаментальное событие человеческой истории - разрыв целостности производства своего материального бытия и соответственно к «... к расщеплению прежней, хотя и неразвитой, но целостной сущности человека и появлению односторонне («частично») развитых индивидов» [3, 351]. Таким образом, разделение труда, интенсификация материального производства обусловило начало фундаментального процесса индивидуализации человеческих сущностных сил.

Первоначально нормы обычаев - передающихся из поколения в поколение наиболее рациональные варианты поведения в социально значимых ситуациях, на ранней стадии первобытного общества в необходимой и достаточной степени выражали общий родовой ин- 
терес, совпадающий с интересом каждого члена рода в отдельности. Необходимости в специальном аппарате принуждения не существовало. Ввиду того, что отдельный человек не мог существовать вне рода, то и личный интерес, а также групповой противопоставленный интересу рода отсутствовал, ввиду отсутствия материального основания такого интереса. Нормы обычаев представляли собой квинтэссенцию родового интереса, задачей которого было самосохранению родовой человеческой сущности, которая в равной степени наполняла всех членов рода. Поскольку такой стихийно выраженный интерес рода не был ничему противопоставлен, кроме такого же интереса в лице другого племени, свободное социальное общение, гипотетически, могло происходить только между такими монолитными общностями.

Систематическое производство избыточного продукта, обуславливает возможность отчуждения такового, поскольку не наносит ущерба воспроизводству жизни производителя, дает возможность субъекту отчуждения не участвовать материальном производстве, а также гарантирует воспроизводство жизни независимо от различных непредвиденных обстоятельств. Именно по поводу избыточного продукта при переходе к производящей экономике начинают складываться отношения частной собственности как института ограничения доступа к материальным либо нематериальным ресурсам иных лиц в пользу собственника.

Сформировавшиеся таким образом различие в социальном положении групп присваивающих прибавочный продукт и тех от кого он отчуждается, формирует возможность освободить часть общинников от материального производства - отделить физический труд от умственного. Социальной функцией частной собственности становится концентрация прибавочного продукта в руках немногочисленных групп, не участвующих в общественном производстве, а выполняющим иные общественные функции, такие как управление и отправление религиозного культа. Положительной стороной накопления прибавочного продукта на одном полюсе общества является возможность совершения значимых качественных преобразований в интересах всего общества, с другой же стороны формирующаяся социальная дифференциация приводит к обнищанию, а далее и к порабощению, непривилегированного большинства.

Право в виде правового обычая возникает в период разложения первобытнообщинного строя именно из необходимости защиты и регуляции отношений частной собственности. В период господства общинной собственности материальные блага, как и прибавочный продукт, принадлежали всем общинникам и необходимости внешнего, стоящего над обществом, способа регуляции как право не существовало. Зарождающийся институт отчуждения прибавочного продукта, произво- димого большинством в пользу меньшинства, требовал внешних по отношению к обществу механизмов защиты интересов меньшинства и его собственности. Возвысившаяся часть общества начинает трансформировать обычаи для своих групповых интересов $[4,10]$.

Обычное право возникает в ту эпоху первобытного строя, когда налицо определенное обособление родоплеменных учреждений от коллективов рода и племен, то есть тогда, когда необходимость типизации поведения человека в более строгих рамках становится условием дальнейшего существования [5, 76]. Право возникает в ответ на глубинную необходимость регламентации поведения субъектов новых отношений эксплуатации, в интересах сохранения всего человеческого рода. Произвол, как объект регламентации выходит за рамки интересов человеческого рода и подлежит вытеснению из социума, как явления противостоящего сохранению и возможности развития человеческого рода.

Очевидно, что закрепление института частной собственности на отчужденный продукт встречали сопротивление и неприятие со стороны определенной части коллектива. Это неприятие выражалось в непризнании и неподчинении правилам отчуждения, распределения и обмена прежде общей родовой собственности. Именно в начальный период поляризации первобытного общества мы можем гипотетически смоделировать возможность проявления правового нигилизма в его наиболее полном и ярком виде, поскольку в лице правового, юридического обычая и права частной собственности отрицался правовой, нормативный порядок в целом. Выступая против эксплуатации и порабощения, основанном на праве в той или иной его форме, прежде, свободные общинники сталкивались с отпором родоплеменной знати. У общинников, выступавших против нормативного порядка, закрепляющего отчуждение прибавочного продукта в пользу верхушки общества, еще были перед глазами обычаи предков, согласно которым исключений из общей родовой собственности не допускалось, и именно в этом моменте их неприятие права и всего порядка с ним связанного - эксплуатации и отчуждения, носило наиболее глубинный, сущностный характер. В последующие эпохи такого зримого противопоставления потестарного, общественного устройства социальному расслоению, и соответственно выраженного в них обычного и правового порядка не существовало.

Появление института публичной власти связано с необходимостью защиты частной собственности сначала на отчужденный прибавочный продукт, а затем на сами средства производства, которые являются источником не только прибавочного, но и необходимого для воспроизводства жизни производителя продукта. Формируется устойчивое социальное неравенство, основанное на отношении одних социальных групп к средствам произ- 
водства как находящимся в их частной собственности, а других групп как им не принадлежащим, либо социальная группа, сама являясь средством производства, оказывается в частной собственности господствующего слоя.

Государство, политическая организация прежде однородного общества, выступает в отношении к отдельным его членам как отчужденное от них и стоящее над ними инобытие родовой сущности человека, как институциализированная проекция, преломление, всеобщей воли человеческого рода. Таким местом преломления и трансформации всеобщей воли рода становится особый репрезентант рода - господствующий класс, элита, конкретно-исторический носитель родовой человеческой сущности. Проходя через сознание господствующего класса, воля рода возвращается к каждому конкретному индивиду в виде правовых установлений.
Интересы правящей верхушки во многом противостоят интересам народа, а интересы всего рода избирательно как соответствуют так и противостоит интересам того и другого класса. Родовой интерес должен возвышаться над интересами, как элиты, так и народа, снимать их противоречия. Правящий класс артикулирует через правовые механизмы волю рода, исходя, прежде всего, из своих, классовых интересов. Родовая воля, приобретая нормативную форму и санкционируемая государством, всегда будет обусловлена интересам прежде всего правящего класса, который лишь формально выражает всеобщую волю. В сущности же, артикулируемая правящим слоем, всеобщая воля рода лишь отчасти является таковой. Данный зазор между объективной волей рода и наличным, сущностным выражением её в законодательстве всегда будет субстанциональной основой правового нигилизма в классовом обществе.

\section{ЛИТЕРАТУРА}

1. Матузов Н.И. Актуальные проблемы теории права. Саратов, 2003.588 с.

2. Матузов Н.И. Правовой нигилизм и правовой идеализм как две стороны «одной медали» /Н.И. Матузов. //Правоведение. -1994. - № 2. С. 3-8.

3. Мусаелян Л.А. Научная теория исторического процесса: становление и сущность. // Издательство Пермского государственного университета. Пермь. 2011.439 c.

4. Кузнецова Н.Ф. Преступление и преступность. М., 1969. 232 с.

5. Трубецкой Е.Н. Лекции по энциклопедии права. М., 1917. 227 с.

○ Белкин Василий Владимирович (consigliori2003@mail.ru).

Журнал «Современная наука: актуальные проблемы теории и практики»

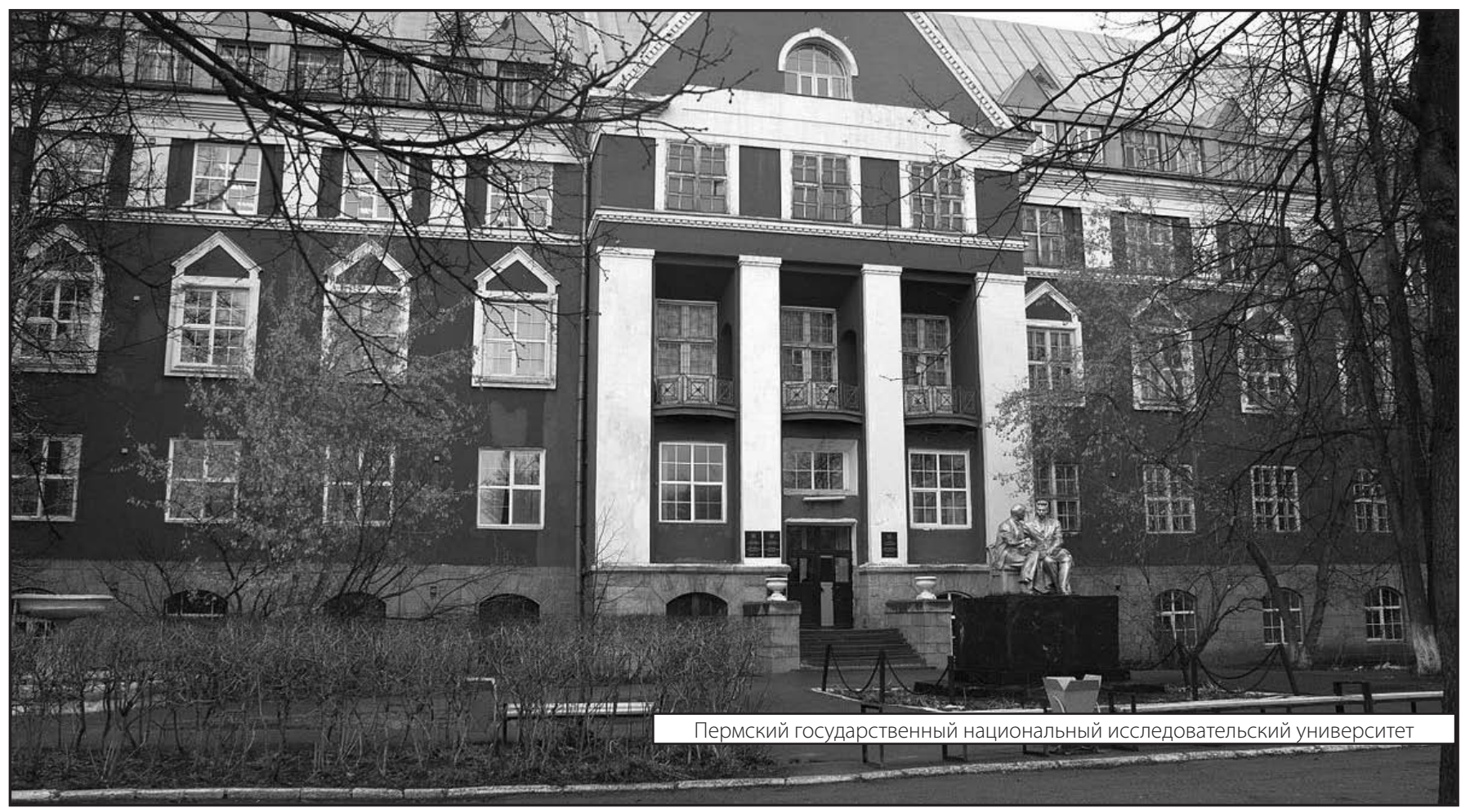

